\title{
COMPORTAMENTO DE HEDYPATHES BETULINUS (KLUG, 1825) EM ERVA-MATE EM CAMPO
}

\author{
BEHAVIOR OF HEDYPATHES BETULINUS (KLUG, 1825) \\ ON THE PARAGUAY TEA PLANTS
}

\section{Jerson Vanderlei Carús Guedes ${ }^{1}$ Márcia d'Avila ${ }^{2}$ Sylvio Henrique Bidel Dornelles ${ }^{3}$}

RESUMO

Foi avaliado o comportamento de cópula, postura, alimentação e deslocamento da broca da erva-mate, Hedypathes betulinus (Klug, 1825), na área experimental da Universidade Federal de Santa Maria. Essas características da broca foram avaliadas por um período de quatro dias através de observações visuais (de hora em hora), em duas gaiolas teladas colocadas sobre um ramo da planta, e contendo dois casais do inseto/gaiola. Observou-se que o macho, quando acompanhado de uma fêmea, tenta copular imediatamente, realizando cópulas durante todos os períodos do dia, principalmente entre 14 e 18h, e em toda a extensão do ramo. A postura ocorreu nos ramos de $15-20 \mathrm{~mm}$ de diâmetro. A maior intensidade de alimentação ocorreu no período compreendido entre 10 e $18 \mathrm{~h}$, sendo preferencialmente realizada em ramos de $30-40 \mathrm{~mm}$ de diâmetro. $O$ inseto apresentou comportamento sedentário e de fácil localização em função de sua limitada e lenta movimentação. Esses resultados são importantes para localização, amostragem, catação manual e manejo da praga.

Palavras-chave: inseto-praga, Hedypathes betulinus, essência florestal.

\section{SUMMARY}

A trial was carried out in the experimental area of the Universidade Federal de Santa Maria to study the behaviour of mating, egg-laying, feeding and movement of Hedypathes betulinus (Klug, 1825) in the Paraguay tea (Ilex paraguariensis). These characteristics were monitored during four days (hourly) in two screen cages, each envolving a branch of a plant and containing two adult couples of $\boldsymbol{H}$. betulinus. When approaching a female, the male tried to copulate immediately and usually mated several times during the day mainly between 2:00 and 6:00pm and on along the branch. Egg-laying was more frequent on branches between 15 and 20mm in diameter. Feeding ocorred more intensivel y fron 10:00am to 6:00p.m preferently on branches between 30 and $4 \mathrm{~mm}$ in diameter The adults showed limited movement and sedentary behaviour.

Key Words: pest, Hedypathes betulinus, forest plant.

\section{INTRODUÇÃO}

A erva-mate (Ilex paraguariensis) é uma essência florestal de crescente relevância econômica no Rio Grande do Sul, em especial na região de Venâncio Aires, onde é um dos principais sustentáculos da economia (AZEVEDO \& CORSEUIL, 1997). Na década de 70, com o avanço da fronteira agrícola no sul do Brasil e a crescente demanda de madeira, a erva-mate teve sua área diminuída em decorrência da extinção das florestas nativas. Muitos ervais antigos deram lugar, principalmente, às culturas de trigo e soja (IEDE, 1989). Desse modo, o aumento de povoamentos puros e a interferência do homem no ambiente foram os principais fatores responsáveis pelo desequilíbrio nos ecossistemas, bem como sobre a entomofauna, determinando a ocorrência de pragas e maiores danos aos cultivos (PENTEADO, 1995).

A principal praga da erva-mate é o Hedypathes betulinus (Klug, 1825) (Coleoptera:

\footnotetext{
${ }^{1}$ Engenheiro Agrônomo, Professor Assistente, Departamento de Defesa Fitossanitária, Centro de Ciências Rurais, Universidade Federal de Santa Maria (UFSM), Santa Maria, RS. E-mail: jcguedes@ccr.ufsm.br. Autor para correspondência.

${ }^{2}$ Engenheira Florestal, Pós-graduando em Engenharia Florestal, UFSM.

${ }^{3}$ Engenheiro Agrônomo, Professor Assistente, Departamento de Biologia, Centro de Ciências Naturais e Exatas, UFSM. 
Cerambycidae), conhecido como corintiano ou broca da erva-mate, que causa severos danos e grandes perdas econômicas nas erveiras (CASSANELLO, 1993). Os danos são mais significativos onde a poda debilita as árvores, tornando-as mais vulneráveis ao ataque da praga. $\mathrm{O}$ inseto adulto mede, aproximadamente, $25 \mathrm{~mm}$ de comprimento, de coloração branca com desenhos escuros no protórax e nos élitros. As antenas são longas e finas e apresentam manchas brancas e escuras alternadas (IEDE, 1985). As fêmeas efetuam as posturas, colocando um ovo em cada galho. As larvas são ápodes, brancas e broqueiam os ramos e tronco das ervas. Constroem galerias no sentido longitudinal dos troncos e galhos da planta, que impedem a circulação normal da seiva, resultando no depauperamento das erveiras (BRANDÃO FILHO, 1945). à medida que perfura o tronco, a larva deixa atrás de si uma serragem, que vai se acumulando na base do caule, denunciando a presença da broca, que chega a destruir $60 \%$ dos ervais (MAZUCHOWSKI, 1991).

Com o objetivo de estudar lacunas do comportamento da broca da erva-mate em campo, este trabalho foi conduzido na área experimental da Universidade Federal de Santa Maria, Santa Maria RS, durante o mês de fevereiro de 1999. As observações foram realizadas em duas erveiras. Cada uma das plantas teve um ramo coberto por uma gaiola piramidal $(1,70 \mathrm{~m}$ de comprimento, $0,70 \mathrm{~m}$ na extremidade maior e $0,30 \mathrm{~m}$ na extremidade menor, recobertas com uma tela de nylon) localizada a $1,75 \mathrm{~m}$ do solo. Em cada gaiola, foram introduzidos dois casais do inseto, obtidos em campo, cujo comportamento foi monitorado continuamente, de hora em hora, durante quatro dias. Os parâmetros avaliados foram cópula, postura, alimentação e deslocamento do inseto na planta.

Observou-se que no período de pré-cópula o inseto apresentou movimentação lenta e hábito sedentário, justificando o cortejamento simples. Esse período foi inferior a um minuto, seguido imediatamente da cópula. $\mathrm{O}$ macho, ao detectar uma fêmea receptiva, iniciou prontamente a monta, prendendo-a com o $1^{\circ}$ e o $2^{-}$par de patas, sendo que o $1^{\underline{0}}$ par localiza-se na altura dos élitros e o $2^{\underline{0}}$ par no final do abdômen da fêmea. Logo após a monta, o macho curvou seu abdômen para a frente, tentando consumar $\mathrm{o}$ ato sexual. A fêmea permaneceu na posição normal de caminhamento e, muitas vezes, locomoveu-se e alimentou-se com o macho sobre ela. Na maioria das cópulas, observou-se que as antenas do macho se deslocavam para trás ficando ao longo do seu corpo. O comportamento mais comum foi a permanência do macho sobre a fêmea durante um longo período, no qual várias cópulas foram observadas. Foi observada a capacidade do mesmo macho copular com mais de uma fêmea, confirmando resultados de GALILEO et al. (1993) e SOARES (1998). Ao final da cópula, o macho separou a genitália e continuou na mesma posição de monta, na maioria das vezes por um longo período. Em muitos casos, o macho simplesmente subiu no dorso da fêmea sem procurar sua genitália, caracterizando a fase passiva de Parker (Thornhill \& Alcock apud VIANA \& VILELA, 1996). Nessa posição, o macho impediu que outro macho montasse sua parceira, podendo ser essa a razão pela qual permaneçam por tanto tempo sobre as fêmeas. As cópulas ocorreram, praticamente, em todas as horas do dia, e em todas as partes do galho, inclusive na tela da gaiola, não demonstrando preferência por local específico na planta. O maior número de cópulas ocorreu no período da tarde e início da noite (Figura 1), sendo que ocorreu 4,3 cópulas/casal/dia, durando em média 12,1 minutos, cada uma. A fêmea, após ter escolhido o local apropriado para a postura, preparou uma cavidade de aproximadamente $5-7 \mathrm{~mm}$ de comprimento e $2-3 \mathrm{~mm}$ de profundidade, perpendicular ao sentido do galho. Ao término dessa operação, a fêmea realizou um giro de $180^{\circ}$ e com o seu ovopositor realizou a postura. Para o fechamento da cavidade, a fêmea voltou à posição

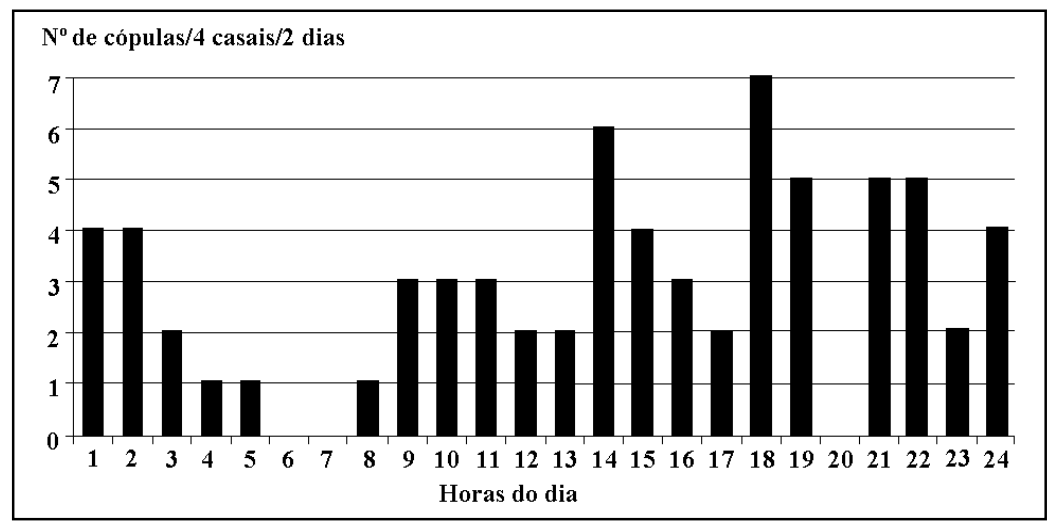

Figura 1 - Número de casais de Hedypathes betulinus copulando em Ilex paraguariensis ao longo do dia durante o período experimental. Santa Maria, RS. 1999. 
inicial e fez uma mistura de casca com lenho, cobrindo totalmente o ovo. Para a realização das posturas, foi observada a preferência por galhos com diâmetros de aproximadamente 15-20mm. Em função da caprichosa proteção da postura, essa é de difícil localização, o que torna difícil a coleta por pessoas menos treinadas.

Os maiores danos, devido à roedura pelos adultos ocorreram nos galhos de maior diâmetro (30$40 \mathrm{~mm}$ ), observando-se também a alimentação da casca de ramos verdes, ou tenros. Algumas vezes, ocorreu da fêmea alimentar-se durante ou após a cópula. Verificou-se, também, que os adultos roíam o pecíolo das folhas até a sua queda e, em seguida, alimentavam-se do pecíolo danificado. Observação semelhante foi relatada por SOARES (1998). Verificou-se que a maior intensidade de alimentação do inseto ocorreu no período compreendido entre 10 e 18 horas, para ambos os sexos, sendo as fêmeas mais vorazes que os machos (Figura 2). O tempo médio de alimentação foi de 23,7 minutos, ocorrendo 1,4 alimentações/inseto/dia. Os adultos de $\boldsymbol{H}$. betulinus apresentaram movimentação lenta, permanecendo parados por longos períodos sobre o ramo ou a tela. Também foi detectada a preferência do inseto em ocupar os extremos dos ramos, comportamento possivelmente associado aos vôos de dispersão. Quando encontrados junto à base do ramo, geralmente tratava-se de fêmea em busca de local para postura ou macho à sua procura. Este comportamento de permanecer alimentando-se, copulando ou imóvel nos ramos da planta facilita sua observação e, somandose aos horários de maiores atividades dos mesmos, permitem inferir que práticas visando à localização e à catação do $\boldsymbol{H}$. betulinus devem ser afetuadas durante o dia até as primeiras horas da noite.

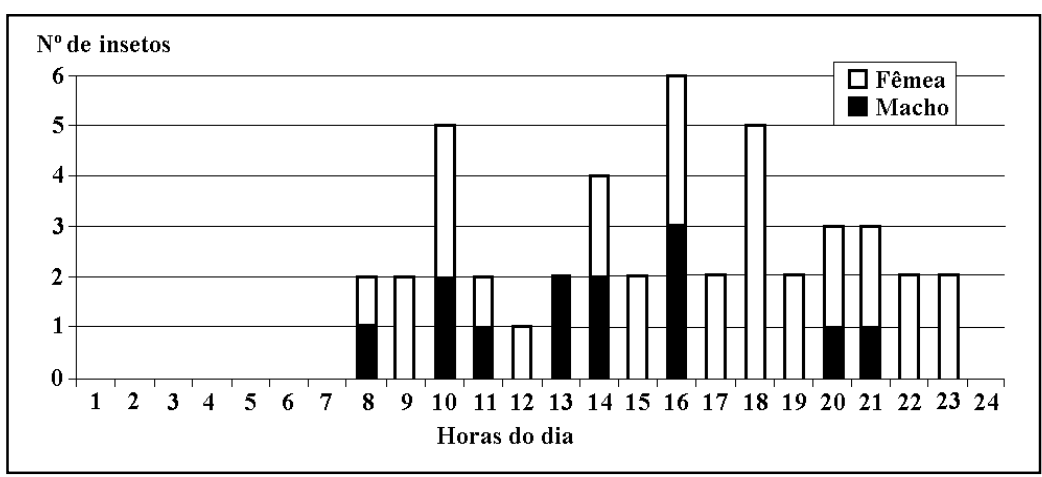

Figura 2 - Número de Hedypathes betulinus alimentando-se em Ilex paraguariensis ao longo do dia durante o período experimental. Santa Maria, RS. 1999.

\section{REFERÊNCIAS BIBLIOGRÁFICAS}

AZEVEDO, E.C.G., CORSEUIL, E. Detecção de feromônios em Hedypathes betulinus (Coleoptera, Cerambycidae), em laboratório. In: CONGRESSO BRASILEIRO DE ENTOMOLOGIA, 1997, Salvador. Anais... Salvador, SEB/EMBRAPA, 1997. 400p. p.65.

BRANDÃO FILHO, J.S. Uma broca do mate. Boletim Agrícola Secção Formação Agrícola, Curitiba, v.3, n.8/9, p.55-58, 1945 .

CASSANELLO, A.M.L. Ciclo de vida e aspectos morfológicos de Hedypathes betulinus (Klug,1825) (Coleoptera, Cerambycidae, Lamiinae), broca-da-erva-mate (Ilex paraguariensis St. Hil.). Curitiba, PR, 1993. 59p. Dissertação (Mestrado em Entomologia) - Curso de Pósgraduação em Ciências Biológicas, Universidade Federal do Paraná, 1993.

GALILEO, M.H.M., MARTINS, U.R., MOURA, L. DE A Sobre o comportamento, ontogenia e morfologia do aparelho reprodutor de Hedypathes betulinus (Klug,1825) (Coleoptera, Cerambycidae, Lamiinae, Aconthoderini) a broca da erva-mate. Revista Brasileira de Entomologia, São Paulo, v.37, n.4, p.705-715, 1993.

IEDE, E.T. Considerações sobre a Entomofauna da Erva-Mate (Ilex paraguariensis St. Hil.). In: SEMINÁRIO SOBRE ATUALIDADES E PERSPECTIVAS FLORESTAIS. Silvicultura da Erva-Mate, 1983, Curitiba, PR. Anais... Curitiba : EMBRAPA, 1985. 145p. p.1 11-118.

IEDE, E.T., MACHADO, D. Pragas da Erva-Mate (Ilex paraguariensis St. Hil.) e seu controle. Boletim Pesquisa Florestal, Curitiba, n.18/19, p.51-60, 1989.

MAZUCHOWSKI, J.Z. Manual da Erva-Mate (Ilex paraguariensis St. Hil.). Curitiba : EMATER, 1991. 104p.

PENTEADO, S. DO R.C. Principais pragas da erva-mate e medidas alternativas para seu controle. In: WINGLE, H., FERREIRA, A.G., MARIATH, J.E. DE A., et al. Erva mate: Biologia e cultivo no cone-sul. Porto Alegre: UFRGS, 1995, 356p. p.109-120.

SOARES, C.M.S. Flutuação populacional, aspectos comportamentais e levantamento de inimigos naturais de Hedypathes betulinus (Klug, 1825) (Coleoptera: Cerambycidae), em um povoamento puro de erva-mate (Ilex paraguariensis St. Hil.). Curitiba, PR, 1998 73p. Tese (Doutorado em Entomologia)- Curso de Pós-graduação em Ciências Biológicas, Universidade Federal do Paraná, 1998.

VIANA, A.M.M., VILELA, E.F. Comportamento de corte e acasalamento de Cosmopolites sordidus Germar (Coleoptera: Curculionidae). Anais da Sociedade Entomológica do Brasil, Piracicaba, SP, v.25, n.2, p.347-350, 1996.

Ciência Rural, v. 30, n. 6, 2000. 